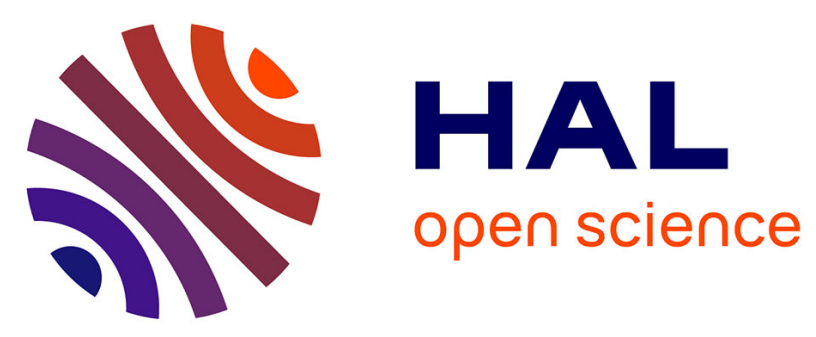

\title{
Correlating Structure with Threshold Behavior of Chalcogenide Glasses Within Ge-Sn-Se Ternary System
}

Beijing Qiao, Feifei Chen, Yicong Huang, Ruiqiang Lin, Xiaoyu Zhang, Shixun Dai, Xiang Shen, Qiuhua Nie, Xianghua Zhang

\section{> To cite this version:}

Beijing Qiao, Feifei Chen, Yicong Huang, Ruiqiang Lin, Xiaoyu Zhang, et al.. Correlating Structure with Threshold Behavior of Chalcogenide Glasses Within Ge-Sn-Se Ternary System. Journal of the American Ceramic Society, 2017, 100 (1), pp.108-114. 10.1111/jace.14477 . hal-01500401

HAL Id: hal-01500401

https://hal-univ-rennes1.archives-ouvertes.fr/hal-01500401

Submitted on 23 May 2017

HAL is a multi-disciplinary open access archive for the deposit and dissemination of scientific research documents, whether they are published or not. The documents may come from teaching and research institutions in France or abroad, or from public or private research centers.
L'archive ouverte pluridisciplinaire HAL, est destinée au dépôt et à la diffusion de documents scientifiques de niveau recherche, publiés ou non, émanant des établissements d'enseignement et de recherche français ou étrangers, des laboratoires publics ou privés. 


\title{
Correlating structure with threshold behavior of
}

\section{chalcogenide glasses within Ge-Sn-Se ternary system}

\author{
Beijing Qiao, ${ }^{1,2}$ Feifei Chen, ${ }^{1,2}$ Yicong Huang, ${ }^{1,2}$ Ruiqiang Lin, ${ }^{1,2}$ Xiaoyu Zhang, ${ }^{1,2}$ Shixun Dai, ${ }^{1,2}$ Xiang \\ Shen, ${ }^{1,2}$ Qiuhua Nie, ${ }^{1,2}$ and Xianghua Zhang ${ }^{2}$ \\ ${ }^{1}$ Laboratory of Infrared Materials and Devices, The Research Institute of Advanced Technologies, Ningbo \\ University, Fenghua Load No. 818, Ningbo 315211, China \\ ${ }^{2}$ Key Laboratory of Photoelectric Detection Materials and Devices of Zhejiang Province, Ningbo University, \\ Fenghua Load No. 818, Ningbo 315211, China \\ ${ }^{3}$ Laboratory of Glasses and Ceramics, UMR 6226 CNRS-University of Rennes 1, Rennes Cedex 135042, \\ France \\ ${ }^{*}$ Corresponding author: chenfeifeil @nbu.edu.cn
}

\begin{abstract}
A systematic investigation of the optical and structural properties of chalcogenide glasses in $\mathrm{Ge}-\mathrm{Sn}-\mathrm{Se}$ ternary system is presented. We have found a threshold behavior of optical property, namely, existence of transitional composition of the Ge-Sn-Se glasses, with progressive replacement of Se by Sn. Calculation of mean coordination number indicates that the transition-like feature of optical property is associated with the evolution of chemical ordering of the Ge-Sn-Se network. Analysis of Raman spectra of the glasses explains that the interaction between $\mathrm{Se}-\mathrm{Se}$ bonds, $\mathrm{Sn}\left(\mathrm{Se}_{1 / 2}\right)_{4}$ tetrahedra, and $\mathrm{Sn}-\mathrm{Sn}$ homopolar bonds is the origination of such optical phenomenon.
\end{abstract}

Keywords: Chalcogenides; glasses; optical materials/properties.

\section{Introduction}

Selenium-based chalcogenide glasses ( $\mathrm{Se}-\mathrm{ChGs}$ ) refer to a group of amorphous materials that contain chalcogen element Se as main constructing units that are covalently bonded with other glass-forming elements, such as As, 
$\mathrm{Ge}$, and $\mathrm{Sb}$. These Se-ChGs are well known ${ }^{1-3}$ for their large third-order nonlinear (TONL) susceptibility $\left(\chi^{(3)}\right.$, magnitude of two orders larger than that of silica glass) and exceptional infrared transparency with a spectral range from $\sim 1 \mu \mathrm{m}$ to over $15 \mu \mathrm{m}$. With the rapid development of infrared technologies, a number of recent studies ${ }^{4-7}$ have realized the fabrication of Se-ChG-based infrared photonic devices with high performance that utilize the high TONL susceptibility and form flexibility, such as bulk, fiber, thin film, and solute.

The TONL susceptibility of amorphous materials has wavelength dependence as a result of multi-photon absorption (MPA). ${ }^{8}$ For Se-ChGs, the MPA behavior can be influenced by the photoinduced phenomena caused by the flexibility of their network structure and presence of defect states. Therefore, a reliable method to tune the TONL susceptibility of Se-ChGs is to engineer their optical bandgap energy $\left(E_{\mathrm{g}}\right),{ }^{9,10}$ which is related to density of defect states and chemical compositions of the glasses. Early studies ${ }^{11-13}$ have reported a threshold behavior of $E_{\mathrm{g}}$ value in various $\mathrm{Se}-\mathrm{ChGs}$ systems, such as $\mathrm{Ge}-\mathrm{Se}, \mathrm{Ge}-\mathrm{As}-\mathrm{Se}$, and $\mathrm{Ge}-\mathrm{Sb}-\mathrm{Se}$. Prasad et al. ${ }^{12}$ found that such threshold behavior in Ge-As-Se glasses was associated with the total number of homopolar bonds. In our recent research ${ }^{13}$ on $\mathrm{Ge}-\mathrm{Sb}-\mathrm{Se}$ glasses, we discovered that threshold behavior was also related to the type of homopolar bonds in the glasses. However, little effort has been focused on finding the threshold behavior in other $\mathrm{Se}-\mathrm{ChG}$ systems, as well as its detailed correlation with structure of glass network.

In this work, tin ( $\mathrm{Sn})$ is selected to replace arsenic (As) and antimony (Sb) considering its environmental friendliness, as well as its improvement to optical transmittance of Ge-containing ChGs. ${ }^{14}$ Two sets of Se-ChGs in germanium-tin-selenium (Ge-Sn-Se) ternary system are selected and synthesized by melt-quenching method. An evident $E_{\mathrm{g}}$ threshold behavior from both sets of Ge-Sn-Se ChGs is observed and its correlation with structure of glass network is studied by Raman spectra.

\section{Experimental}

The ChGs were prepared from high purity polycrystalline of germanium $(5 N)$, tin $(5 N)$ and selenium $(5 N)$. The first set of glasses are in molar composition of $\mathrm{Ge}_{20} \mathrm{Sn}_{\mathrm{x}} \mathrm{Se}_{80-\mathrm{x}}(\mathrm{Ge} 20$ set, $\mathrm{x}=0,5,10,11.5,12.5$ and 13), and the second ones are $\mathrm{Ge}_{15} \mathrm{Sn}_{\mathrm{x}} \mathrm{Se}_{85-\mathrm{x}}(\mathrm{Ge} 15$ set, $\mathrm{x}=0,5,10,13,15,16.5,17.5$ and 18). The raw materials were weighed carefully and mixed in sealed quartz ampoules in vacuum which were then put into rocking furnaces. The quartz 
ampoules were heated to $950{ }^{\circ} \mathrm{C}$ slowly in furnaces and then maintained for $12 \mathrm{~h}$ at this temperature. All of quartz ampoules were quenched in ice water very quickly to avoid crystallization. All of the samples were annealed at the temperature that $20^{\circ} \mathrm{C}$ lower than $T_{\mathrm{g}}$ for $5 \mathrm{~h}$ to minimize internal tension and then slowed down to room temperature. To test optical characteristics of the samples, the glass rods were cut and optically polished to thickness of $0.5 \mathrm{~mm}$.

Density of the samples was measured by using Archimedes method with distilled water as immersion liquid. Differential scanning calorimetry (TA Q2000) was used to obtain translation temperature $\left(T_{\mathrm{g}}\right)$ and crystallization temperature $\left(T_{\mathrm{x}}\right)$ of the GhGs. Powder X-ray diffraction (XRD) patterns were recorded using a Bruker AXS D2 PHASER diffractometer (voltage $=30 \mathrm{kV}$; current $=10 \mathrm{~mA} ; \mathrm{Cu}$ Ka radiation) with a step width of $0.02^{\circ}$ at room temperature to confirm the amorphous state of the ChGs. The infrared transmission spectra in the range of 2.5$20 \mu \mathrm{m}$ were obtained using Nicolet 381 Fourier Transform Infrared spectrometer (FTIR). Absorption spectra were recorded in the range of 400 2500 nm using Perkin-Elmer-Lamda 950 UV-VIS-NIR spectrophotometer. Raman spectra of the samples were obtained through back $\left(180^{\circ}\right)$ scattering configuration with a Renishaw inVia laser confocal Raman spectrometer with an excitation wavelength of $488 \mathrm{~nm}$ and a frequency resolution of \pm 0.15 $\mathrm{cm}^{-1}$, in order to distinguish the vibration energy of different bonds and structural units within the glass network.

\section{Results and Discussion}

The X-ray diffraction patterns of ChGs and two crystallized samples with slightly higher Sn content are shown in Fig. 1. The broad diffraction bands in the patterns of the glass samples confirmed that they are in amorphous state, and further addition of Sn would cause crystallization, as shown by the multiple sharp diffraction peaks. As noted in the figure, the possible assignments of these peaks are $\mathrm{SnSe}_{2}$ (JCPDS-file No.: 23-602) and GeSe 2 (JCPDS-file No.: 16-80), indicating that both Sn and Ge are four coordinated. Notably, from the chemical compositions in Table 1, all glasses present Se-rich compositions, and those in stoichiometry and Se-insufficient prepared using the same procedure cannot form glass. FTIR spectra of the glasses are present in Fig. 2, and it can be seen that both sets of the Ge-Sn-Se ChGs have high infrared transmittance ( $\geqq 60 \%)$ to over $16 \mu \mathrm{m}$.

The relationship between macroscopic properties and chemical ordering of ChGs can be discussed in 
terms of mean coordination number $(\mathrm{MCN}){ }^{15,16}$ For the present $\mathrm{Ge}_{x} \mathrm{Sn}_{y} \mathrm{Se}_{z}(x+y+z=100)$ glasses, MCN was given by the formula:

$$
\mathrm{MCN}=\left(x \mathrm{CN}_{\mathrm{Ge}}+y \mathrm{CN}_{\mathrm{Sn}}+z \mathrm{CN}_{\mathrm{Se}}\right) / 100
$$

where coordination numbers (CNs) of 4, 4, and 2 were accorded to Ge, Sn, and Se, respectively. As shown in Table 1, MCN value increases as Se is further substituted by Sn. Interestingly, the maximum MCN that kept both sets of samples in the amorphous state is 2.66 , which has been considered as the mechanical threshold value for the transition of ChG network from an overconstrained "rigid" phase to a "stress-rigid" phase. ${ }^{17}$ This result demonstrates that $\mathrm{Ge}-\mathrm{Sn}-\mathrm{Se}$ glasses possessing such network structure would present a higher possibility of forming a uniform network, namely, crystallization.

Characteristic temperatures of the ChGs measured by DSC method are shown in Table 1. The replacement of Se by Sn evidently increased $T_{\mathrm{g}}$, which is due to the high coordination number of $\mathrm{Sn}$ restraining the movement of structural units in the glasses. In other words, the connectivity of the Ge-Sn-Se network is enhanced by the incorporation of Sn. By contrast, $T_{\mathrm{x}}$ first appears as $\mathrm{Sn}$ is introduced to the Ge-Se glasses and increases with the increase in Sn content. Then, the value decreases in both $\mathrm{ChG}$ sets as the $\mathrm{MCN}$ value reaches $~ 2.63$, indicating the transition of thermal properties with the evolution of the Ge-Sn-Se network. When Sn was over-doped $(\mathrm{MCN}>2.66)$, structural units related to Sn begin to aggregate and cause fragmentation in the molecular cluster network of the amorphous Ge-Se region, ${ }^{18}$ which promotes the crystallization tendency of glasses. The variation of $T_{\mathrm{g}}$ and $T_{\mathrm{x}}$ results in a decrease in the thermal stability parameter $\left(\Delta T=T_{\mathrm{x}}-T_{\mathrm{g}}\right.$ ) of ChGs with the increase in Sn content. However, most ChGs possess $\Delta T$ over $100{ }^{\circ} \mathrm{C}$ (except those with $\mathrm{MCN}$ over 2.66), indicating that Ge-Sn-Se ChGs present high stability against crystallization as the glass network is maintained in an overconstrained "rigid" phase.

The absorption spectra of Ge-Sn-Se ChGs are shown in Fig. 3. A similar variation in the fundamental absorption band edge (bandgap wavelength) with the addition of Sn can be observed in both glass sets: the bandgap wavelength red shifts remarkably with the first addition of $\mathrm{Sn}$ and then blue shifts with the progressive increase in Sn content. Then, as the MCN value of ChGs reaches 2.63, the bandgap wavelength red shifts again. The fundamental absorption band of ChGs is related to electronic transitions between the long pair (valence) and 
antibonding (conduction) bands, and the optical bandgap energy $\left(E_{\mathrm{g}}\right)$ can be used to numerically present variations in the bandgap wavelength. ${ }^{19}$ For the present $\mathrm{Ge}-\mathrm{Sn}-\mathrm{Se} \mathrm{ChGs}, E_{\mathrm{g}}$ values are estimated from the highabsorption region, where the absorption coefficient $a=1000 \mathrm{~cm}^{-1}$. As seen in Fig. 4, $E_{\mathrm{g}}$ shows a maximum in both glass sets as MCN value reaches 2.63. This observation is similar to those found in $\mathrm{Ge}-\mathrm{As}-\mathrm{Se}^{12}$ and Ge$\mathrm{Sb}-\mathrm{Se}^{11,13}$ ternary systems, whereas the threshold $\mathrm{MCN}$ value of the other two systems presents a slight deviation due to the difference in chemical properties among $\mathrm{As}, \mathrm{Sb}$, and $\mathrm{Sn}$. The transition of $E_{\mathrm{g}}$ value at the MCN threshold between 2.6 and 2.7 can be explained in terms of the "demixing" effect of the glass network ${ }^{13}$, and Tanaka ${ }^{20}$ had demonstrated that the enhanced degree of cross linking of the layers in glass network is the main contribution to the decrease of $E_{\mathrm{g}}$ above the $\mathrm{MCN}$ threshold. Fig. 5 gives the dependence of molar volume $\left(M_{\mathrm{v}}\right)$ of the ChGs on the MCN value, it is clear that the variation of $M_{\mathrm{v}}$ exhibits threshold behavior as well. The maximum $M_{\mathrm{v}}$ in both glass sets was found at $\mathrm{MCN}=2.63$ indicating the condensing of glass network at the threshold point, which supported the experimental results ${ }^{11-13,17}$ that transition of ChGs network from rigid phase to stressed-rigid phase occurred at MCN between 2.6 and 2.7.

On the other hand, it is well-known that bandgap energy of amorphous materials present by $E_{\mathrm{g}}$ has positive dependence on total bonding energy of the corresponding materials. ${ }^{21,22}$ Accordingly, the decrease in $E_{\mathrm{g}}$ as $\mathrm{Sn}$ was first introduced to the Ge-Se network can be attributed to the lowest electronegativity of $\mathrm{Sn}$ in the ternary system $\left(\chi_{\mathrm{Se}}=2.4, \chi_{\mathrm{Ge}}=2.0, \chi_{\mathrm{Sn}}=1.7\right)$. With further addition of $\mathrm{Sn}, E_{\mathrm{g}}$ of the glasses increased until MCN reached the threshold point (2.63), which indicated the variation of total bonding energy of the Ge-Sn-Se network. Therefore, the detailed structure change in glass network after Sn incorporation is needed to be clarified, which can be used to explain the $E_{\mathrm{g}}$ threshold behavior of the Ge-Sn-Se ChGs.

Raman spectra of the Ge-Sn-Se ChGs are shown in Fig. 6, and it should be noted that the peak at $125 \mathrm{~cm}^{-}$ ${ }^{1}$ is the artificial peak due to the superposition of the decreasing flank of the background and the filter implemented in the FT apparatus. Raman spectra of the present ChGs correlate well with the spectra reported earlier from other Se-ChGs. ${ }^{23-25}$ The main peak can be assigned to the overlapping of the vibration modes of Ge-Se bonds $\left(\sim 195 \mathrm{~cm}^{-1}\right)$ and Sn-Se bonds $\left(\sim 184 \mathrm{~cm}^{-1}\right)$ in corner-shearing tetrahedral units. The second largest band at $\sim 260 \mathrm{~cm}^{-1}$ is assigned to the characteristic vibration of $\mathrm{Se}-\mathrm{Se}$ bonds in $\mathrm{Se}_{n}$ chains or rings. The 
appearance of the above-mentioned structural units is also in good agreement with those reported earlier in the similar glass system by FT-IR spectra. ${ }^{26}$

With the addition of Sn, the Raman spectra of the ChGs varied significantly. The most evident evolution of Raman signal present in both ChGs sets is the significant decreasing intensity of Raman band belonging to Se-Se bonds at $\sim 260 \mathrm{~cm}^{-1}$. Besides, it is also apparent that the main peak shifted to a lower energy region as a result of the increasing number of Sn-Se bonds (as noted by red arrow in Fig. 6). These findings indicate the breakage of $\mathrm{Se}-\mathrm{Se}$ chains and increased $\mathrm{Sn}$ number in the outrigger sites of $\mathrm{Sn}\left(\mathrm{Se}_{1 / 2}\right)_{4}$ tetrahedra. ${ }^{26}$ In other words, the chain fragments ( $\mathrm{Se}_{\mathrm{n}}$ chains) have been replaced by the spatial units, namely, $\mathrm{Sn}\left(\mathrm{Se}_{1 / 2}\right)_{4}$ tetrahedra, leading to the formation of an overconstrained glass network. As the MCN of ChGs reached 2.63, the Raman band belonging to Se-Se bonds almost disappears and a new peak appears near $\sim 150 \mathrm{~cm}^{-1}$ (as shown inset of Fig. 6), growing with increasing content of Sn, as confirmed by the increasing integral area of the Raman band shown in Fig. 7. As shown in previous studies, ${ }^{12,13}$ the Raman signal in such energy range belongs to the vibration of homopolar (metal) bonds. For the present Ge-Sn-Se ChGs, this newly formed Raman peak can be reasonably assigned to the vibration of $\mathrm{Sn}-\mathrm{Sn}$ homopolar bonds because the characteristic Raman vibration of $\mathrm{Ge}-\mathrm{Ge}$ homopolar bonds at $\sim 170 \mathrm{~cm}^{-1}$ can only be observed in the spectra of Sn-free ChGs (as indicated in the inset of Fig. 6).

To numerically explain the threshold behavior of the present Ge-Sn-Se ChGs, the energy of heteroatom bonds $(D)$ that are involved in structural variation was calculated by both arithmetic and geometric means according to the relation assumption proposed by Pauling: ${ }^{27}$

$$
\begin{aligned}
& D_{\text {arithmetic }}=\frac{D(\mathrm{~A}-\mathrm{A})+D(\mathrm{~B}-\mathrm{B})}{2}+23\left(\chi_{\mathrm{A}}-\chi_{\mathrm{B}}\right)^{2} \\
& D_{\text {geometric }}=\sqrt{D(\mathrm{~A}-\mathrm{A}) \times D(\mathrm{~B}-\mathrm{B})}+23\left(\chi_{\mathrm{A}}-\chi_{\mathrm{B}}\right)^{2}
\end{aligned}
$$

where $\chi_{\mathrm{A}}$ is the electronegativity of atom $\mathrm{A}$ and $D(\mathrm{~A}-\mathrm{A})$ is the bond energy of the $\mathrm{A}-\mathrm{A}$ homopolar bond, which is similar for atom B. Notably, the Ge-Sn bond does not exist. As presented in the results in Table 2, the heteroatom bonds are considerably stronger than that of homopolar bonds. Thus, the substitution of $\mathrm{Se}-\mathrm{Se}$ bonds by $\mathrm{Sn}-\mathrm{Se}$ bonds in the $\mathrm{Sn}\left(\mathrm{Se}_{1 / 2}\right)_{4}$ tetrahedra would logically increase the total bonding energy in the ternary 
system, leading to increased $E_{\mathrm{g}}$ value. As the $\mathrm{Sn}$ content reaches the threshold value, the number of $\operatorname{Sn}\left(\operatorname{Se}_{1 / 2}\right)_{4}$ tetrahedra begin to become saturated, and excess Sn enters the tetrahedra and substitutes part of Se, leading to the formation of $\mathrm{Sn}-\mathrm{Sn}$ homopolar bonds that reduce the total bond energy of ChGs. However, the conversion of $\mathrm{Se}_{\mathrm{n}}$ chains to $\mathrm{Sn}\left(\mathrm{Se}_{1 / 2}\right)_{4}$ tetrahedra and the formation of $\mathrm{Sn}-\mathrm{Sn}$ homopolar bonds occur simultaneously, as shown by the Raman spectra. Thus, the total bonding energy $E_{\mathrm{g}}$ exhibits a maximum for the first appearance of $\mathrm{Sn}-\mathrm{Sn}$ homopolar bonds at $\mathrm{MCN}=2.63$. As the $\mathrm{Sn}$ content passes the threshold value, $\mathrm{Sn}-\mathrm{Sn}$ bonds dominate the total bonding energy, and decreasing $E_{\mathrm{g}}$ value is observed, which results in the transition of optical properties.

According to information from the above Raman analysis, a possible structural model of the $\mathrm{Ge}-\mathrm{Sn}-\mathrm{Se}$ glasses can be figured out. The schematic in Fig. 8 illustrates the Ge-Sn-Se glass network, as well as its evolution with replacement of Se by Sn. By using the same number of atoms in the three graphs, the glass network evidently becomes compact as the flexible $\mathrm{Se}_{\mathrm{n}}$ chains are replaced by the stable $\mathrm{Sn}\left(\mathrm{Se}_{1 / 2}\right)_{4}$ tetrahedra. This result indicates the increasing possibility of transformation of the glass network from amorphous to uniform (crystallized) structure, which is consistent with results from the above thermal studies. Besides, the number of non-coordinated Se atoms at the border of the glass network decreases significantly as $\mathrm{Sn}$ is introduced, which visually demonstrated the results from an early study ${ }^{18}$ which showed that the addition of Sn could cause fragmentation of the molecular cluster network of Ge-Se glasses.

\section{Conclusions}

As the mean coordination number $(\mathrm{MCN})$ value of $\mathrm{Ge}-\mathrm{Sn}-\mathrm{Se}$ glasses approaches 2.63, an evident threshold behavior is observed: both optical bandgap energy $\left(E_{\mathrm{g}}\right)$ and molar volume $\left(M_{\mathrm{v}}\right)$ of the glasses exhibit the transition-like feature at $\mathrm{MCN}=2.63$. By employing Raman spectra, the threshold behavior of the Ge-Sn-Se glasses has been correlated with the variation of glass structure: the conversion of $\mathrm{Se}-\mathrm{Se}$ bonds in $\mathrm{Se}_{n}$ chains or rings to $\mathrm{Sn}\left(\mathrm{Se}_{1 / 2}\right)_{4}$ tetrahedra with Sn-doping caused increases of the $E_{\mathrm{g}}$ and $M_{\mathrm{v}}$, while depletion of the Se-Se bonds and presence of $\mathrm{Sn}-\mathrm{Sn}$ homopolar bonds at $\mathrm{MCN}=2.63$ results in decreases of the $E_{\mathrm{g}}$ and $M_{\mathrm{v}}$, namely the threshold behavior. Accordingly, modifying and optimizing various properties of the Ge-Sn-Se glasses, which are considered green candidates for photonic devices in infrared systems, are possible. 


\section{Acknowledgments}

This work was partially supported by National Program on the National Natural Science Foundation of China (Grant Nos. 61435009, 61308094). It was also sponsored by K.C. Wong Magna Fund in Ningbo University.

\section{References}

${ }^{1}$ B. J. Eggleton, B. Luther-Davies, and K. Richardson, "Chalcogenide photonics," Nat. Photon, 5[3] 141-48 (2011).

${ }^{2}$ A. B. Seddon, "Chalcogenide glasses: a review of their preparation, properties and applications," J. Non-Cryst. Solids, 184[0] 44-50 (1995).

${ }^{3}$ A. Zakery and S. R. Elliott, "Optical nonlinearities in chalcogenide glasses and their applications, "Springer, (2007).

${ }^{4}$ L. Li, H. Lin, S. Qiao, Y. Zou, S. Danto, K. Richardson, J. D. Musgraves, N. Lu, and J. Hu, "Integrated flexible chalcogenide glass photonic devices," Nat. Photon., 8[8] 643-49 (2014).

${ }^{5}$ C. R. Petersen, U. Møller, I. Kubat, B. Zhou, S. Dupont, J. Ramsay, T. Benson, S. Sujecki, N. Abdel-Moneim, Z. Tang, D. Furniss, A. Seddon, and O. Bang, "Mid-infrared supercontinuum covering the 1.4-13.3 $\mu \mathrm{m}$ molecular fingerprint region using ultra-high NA chalcogenide step-index fibre," Nat. Photon., 8[11] 830-34 (2014).

${ }^{6}$ T. Guangming, S. Soroush, R. He, K. R. Farnood, R. E. Peale, Y. Zhiyong, W. Xunsi, and A. F. Abouraddy, "Robust multimaterial tellurium-based chalcogenide glass fibers for mid-wave and long-wave infrared transmission," Opt. Lett., 39[13] 4009-12 (2014). 
${ }^{7}$ X. Gai, B. Luther-Davies, and T. P. White, "Photonic crystal nanocavities fabricated from chalcogenide glass fully embedded in an index-matched cladding with a high Q-factor (>750,000)," Opt. Express, 20[14] 15503-15 (2012).

${ }^{8} \mathrm{~K}$. Tanaka, "Two-photon optical absorption in amorphous materials," J. Non-Cryst. Solids, 338-340 534-38 (2004).

${ }^{9}$ T. Wang, X. Gai, W. Wei, R. Wang, Z. Yang, X. Shen, S. Madden, and B. Luther-Davies, "Systematic z-scan measurements of the third order nonlinearity of chalcogenide glasses," Opt. Mater. Express, 4[5] 1011$22(2014)$.

${ }^{10}$ I. Sebastian, S. Mathew, V. P. N. Nampoori, P. Radhakrishnan, and S. Thomas, "Concentration tuned bandgap and corresponding nonlinear refractive index dispersion in Ga-Ge-Se nanocolloids," J. Appl. Phys., 114[5] 053102 (2013).

${ }^{11}$ A. Srinivasan, K. N. Madhusoodanan, E. S. R. Gopal, and J. Philip, "Observation of a threshold behavior in the optical band gap and thermal diffusivity of Ge-Sb-Se glasses," Phys. Rev. B, 45[14] 8112-15 (1992).

${ }^{12}$ A. Prasad, C.-J. Zha, R.-P. Wang, A. Smith, S. Madden, and B. Luther-Davies, "Properties of $\mathrm{Ge}_{\mathrm{x}} \mathrm{As}_{\mathrm{y}} \mathrm{Se}_{1-\mathrm{x}-\mathrm{y}}$ glasses for all-optical signal processing," Opt. Express, 16[4] 2804-15 (2008).

${ }^{13}$ W.-H. Wei, R.-P. Wang, X. Shen, L. Fang, and B. Luther-Davies, "Correlation between Structural and Physical Properties in Ge-Sb-Se Glasses," J. Phys. Chem. C, 117[32] 16571-76 (2013).

${ }^{14}$ I. Haruvi-Busnach, J. Dror, and N. Croitoru, "Chalcogenide glasses Ge-Sn-Se, Ge-Se-Te, and Ge-Sn-Se-Te for infrared optical fibers," J. Mater. Res., 5[6] 1215-23 (1990).

${ }^{15}$ K. Tanaka, "Layer structures in chalcogenide glasses," J. Non-Cryst. Solids, 103[1] 149-50 (1988).

${ }^{16}$ J. C. Phillips, "Topology of covalent non-crystalline solids I: Short-range order in chalcogenide alloys," J. NonCryst. Solids, 34[2] 153-81 (1979).

${ }^{17}$ J. C. Phillips and M. F. Thorpe, "Constraint theory, vector percolation and glass formation," Solid State Commun., 53[8] 699-702 (1985). 
${ }^{18}$ J. M. Mikrut and L. E. McNeil, "Fragmentation of the molecular cluster network of amorphous $\mathrm{Ge}_{1-\mathrm{x}} \mathrm{Sn}_{\mathrm{x}} \mathrm{Se}_{2}, "$ J. Non-Cryst. Solids, 109[2-3] 237-46 (1989).

${ }^{19}$ J. Tauc and A. Menth, "States in the gap," J. Non-Cryst. Solids, 8-10 569-85 (1972).

${ }^{20}$ K. Tanaka, "Structural phase transitions in chalcogenide glasses," Phys. Rev. B, 39[2] 1270-79 (1989).

${ }^{21}$ H. Guo, C. Hou, F. Gao, A. Lin, P. Wang, Z. Zhou, M. Lu, W. Wei, and B. Peng, "Third-order nonlinear optical properties of $\mathrm{GeS}_{2}-\mathrm{Sb}_{2} \mathrm{~S}_{3}-\mathrm{CdS}$ chalcogenide glasses," Opt. Express, 18[22] 23275-84 (2010).

${ }^{22}$ G. Tao, H. Guo, L. Feng, M. Lu, W. Wei, and B. Peng, "Formation and Properties of a Novel Heavy-Metal Chalcogenide Glass Doped with a High Dysprosium Concentration," J. Am. Ceram. Soc., 92[10] 222629 (2009).

${ }^{23}$ R. Holomb, V. Mitsa, E. Akalin, S. Akyuz, and M. Sichka, "Ab initio and Raman study of medium range ordering in $\mathrm{GeSe}_{2}$ glass," J. Non-Cryst. Solids, 373-374[0] 51-56 (2013).

${ }^{24}$ A. B. Adam, "Infrared and Raman studies on $\mathrm{Sn}_{\mathrm{x}}-\mathrm{Sb}_{5}-\mathrm{Se}_{95-\mathrm{x}}$ chalcogenide glasses," J. King Saud Univ. - Sci., 21[2] 93-97 (2009).

${ }^{25}$ R. Zhang, J. Ren, H. Jain, Y. Liu, Z. Xing, and G. Chen, "In-situ Raman spectroscopy study of photoinduced structural changes in Ge-rich chalcogenide films," J. Am. Ceram. Soc., 97[5] 1421-24 (2014).

${ }^{26} \mathrm{~S}$. A. Fayek, "The effects of Sn addition on properties and structure in Ge-Se chalcogenide glass," Infrared Phys. Techn., 46[3] 193-98 (2005).

${ }^{27}$ L. Pauling, "The Nature of the Chemical Bond and the Structure of Molecules and Crystals: An Introduction to Modern Structural Chemistry." Cornell University Press, (1960). 


\section{Figure captions}
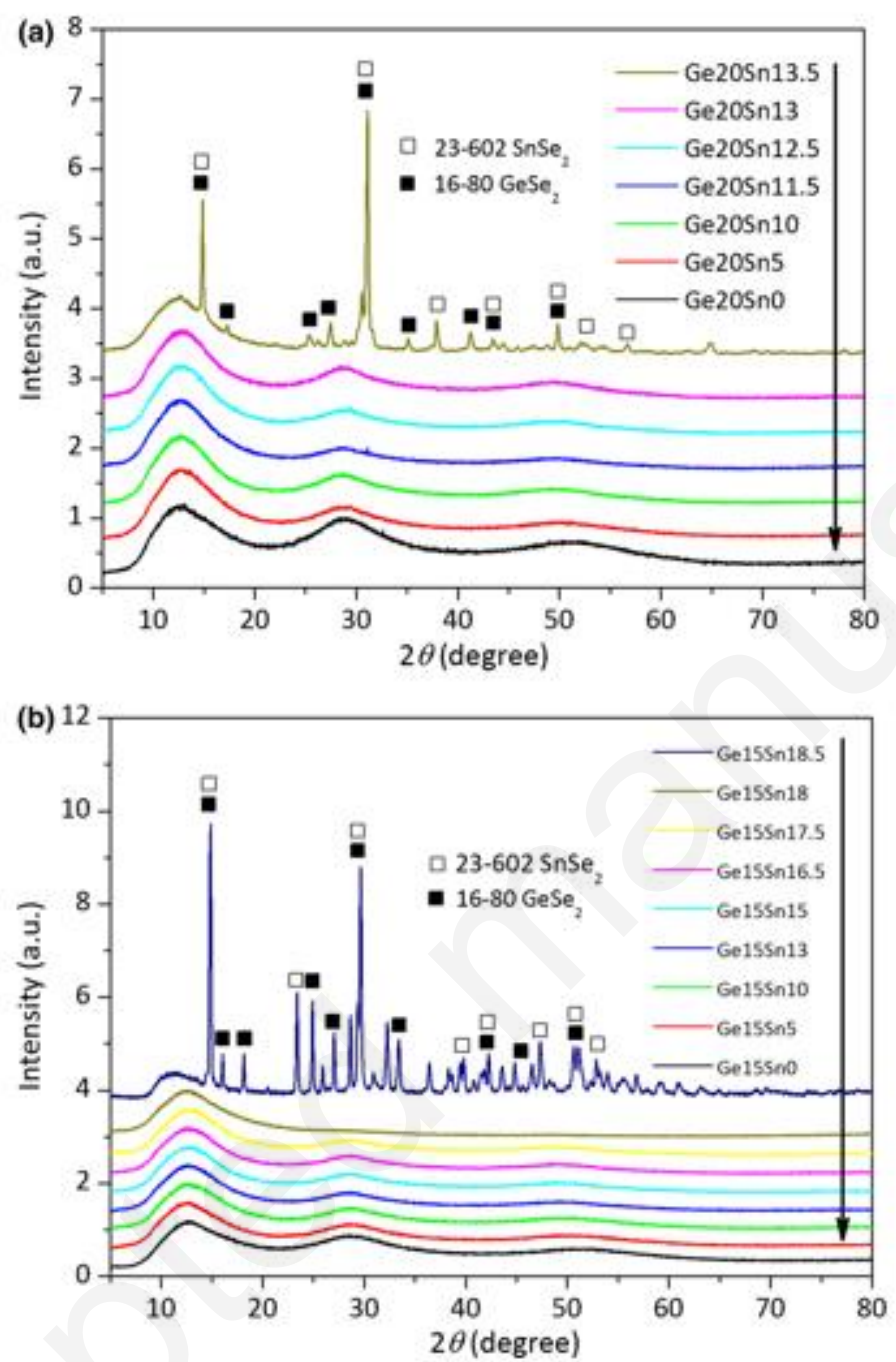

Fig. 1 X-ray diffraction patterns of the Ge-Sn-Se glasses (a) Ge20 set and a crystallized sample in molar composition of $\mathrm{Ge}_{20} \mathrm{Sn}_{13.5} \mathrm{Se}_{66.5}$; (b) Ge15 set and a crystallized sample in molar composition of $\mathrm{Ge}_{15} \mathrm{Sn}_{18.5} \mathrm{Se}_{66.5}$. 

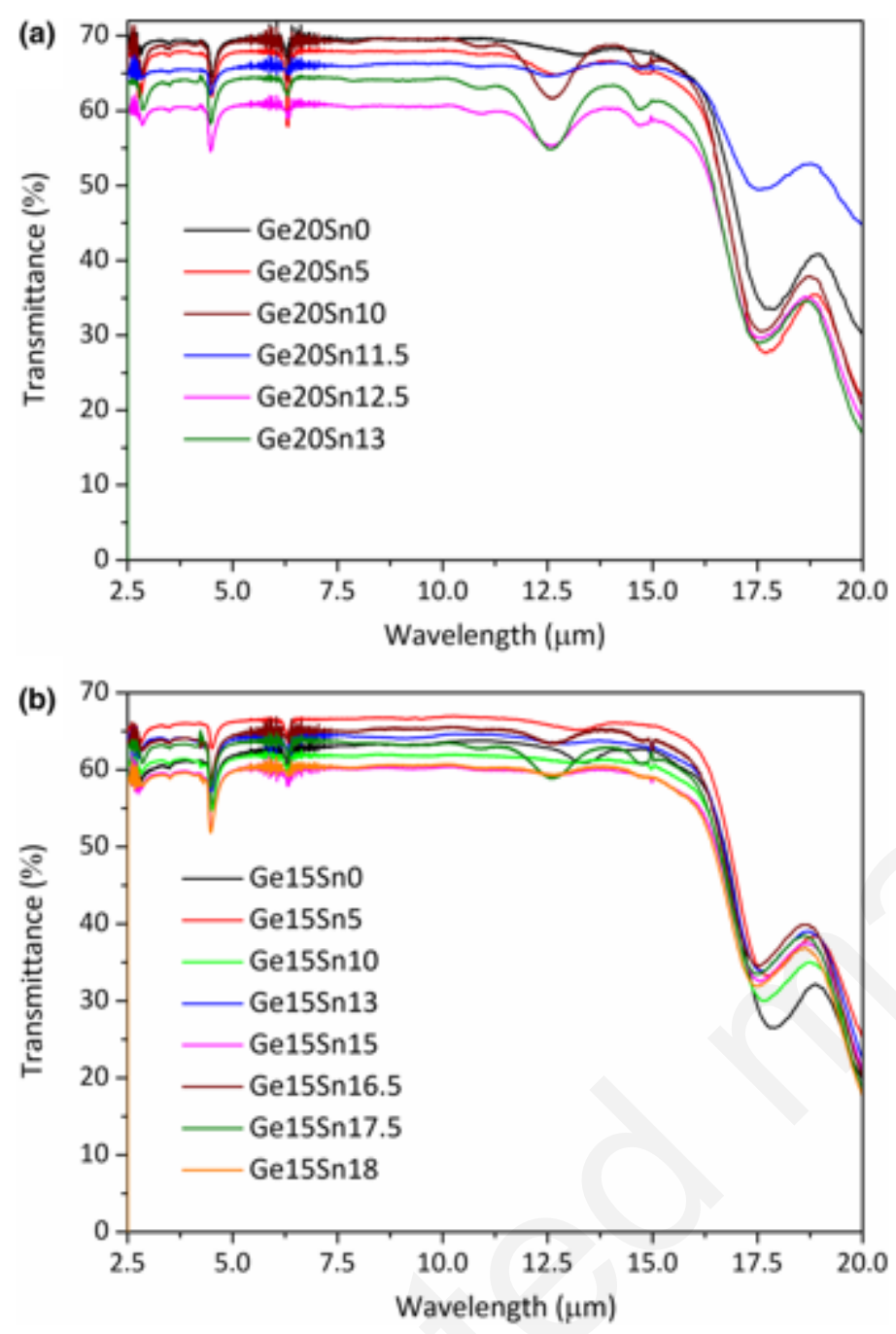

Fig. 2 FT-IR transmittance spectra of the Ge-Sn-Se glasses (a) Ge20 set and (b) Ge15 set. 

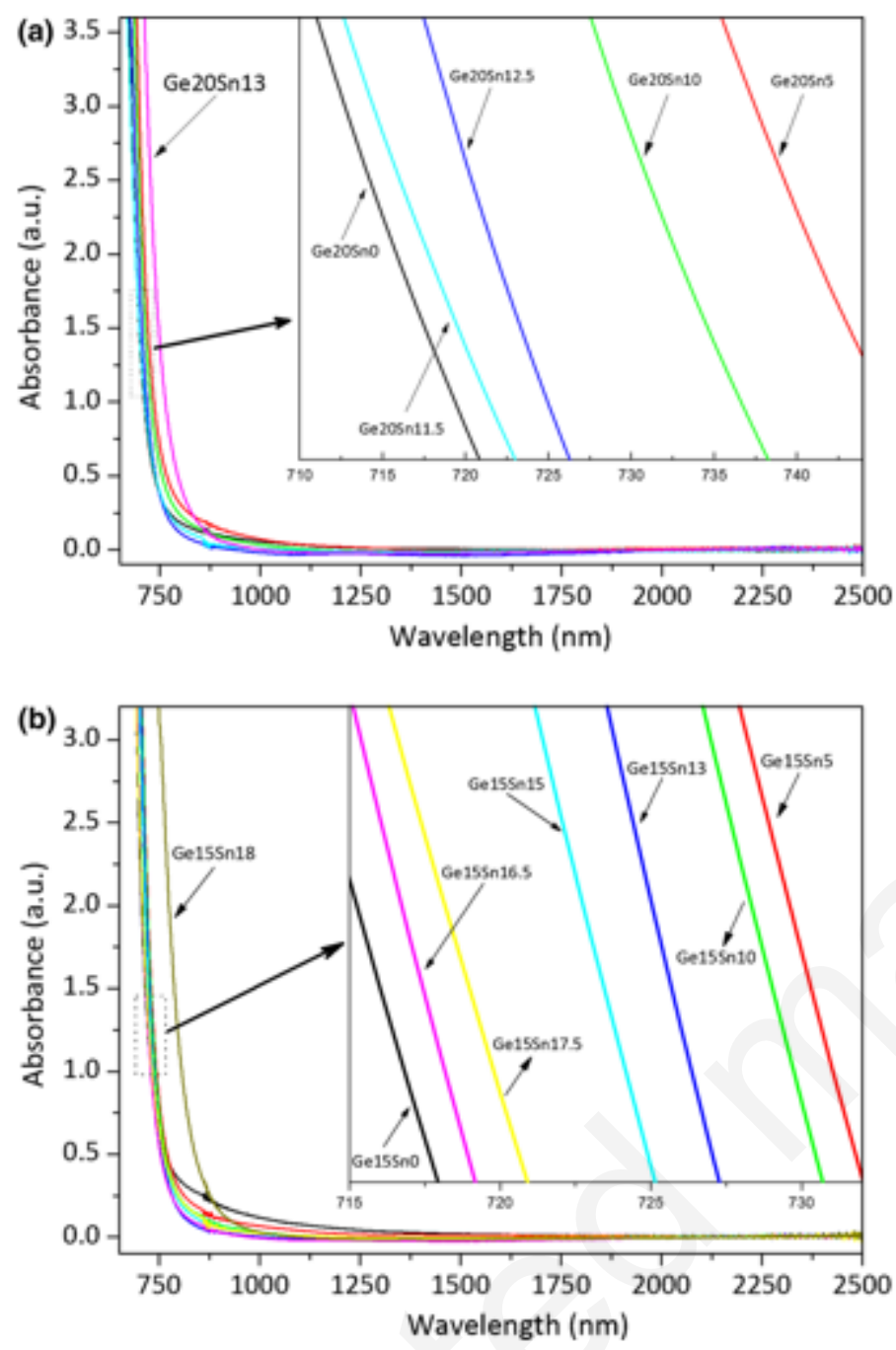

Fig. 3 Absorption spectra of the Ge-Sn-Se glasses (a) Ge20 set and (b) Ge15 set. In the inset, the absorption spectra are enlarged to show the variation tendency of the UV fundamental absorption band edge. 


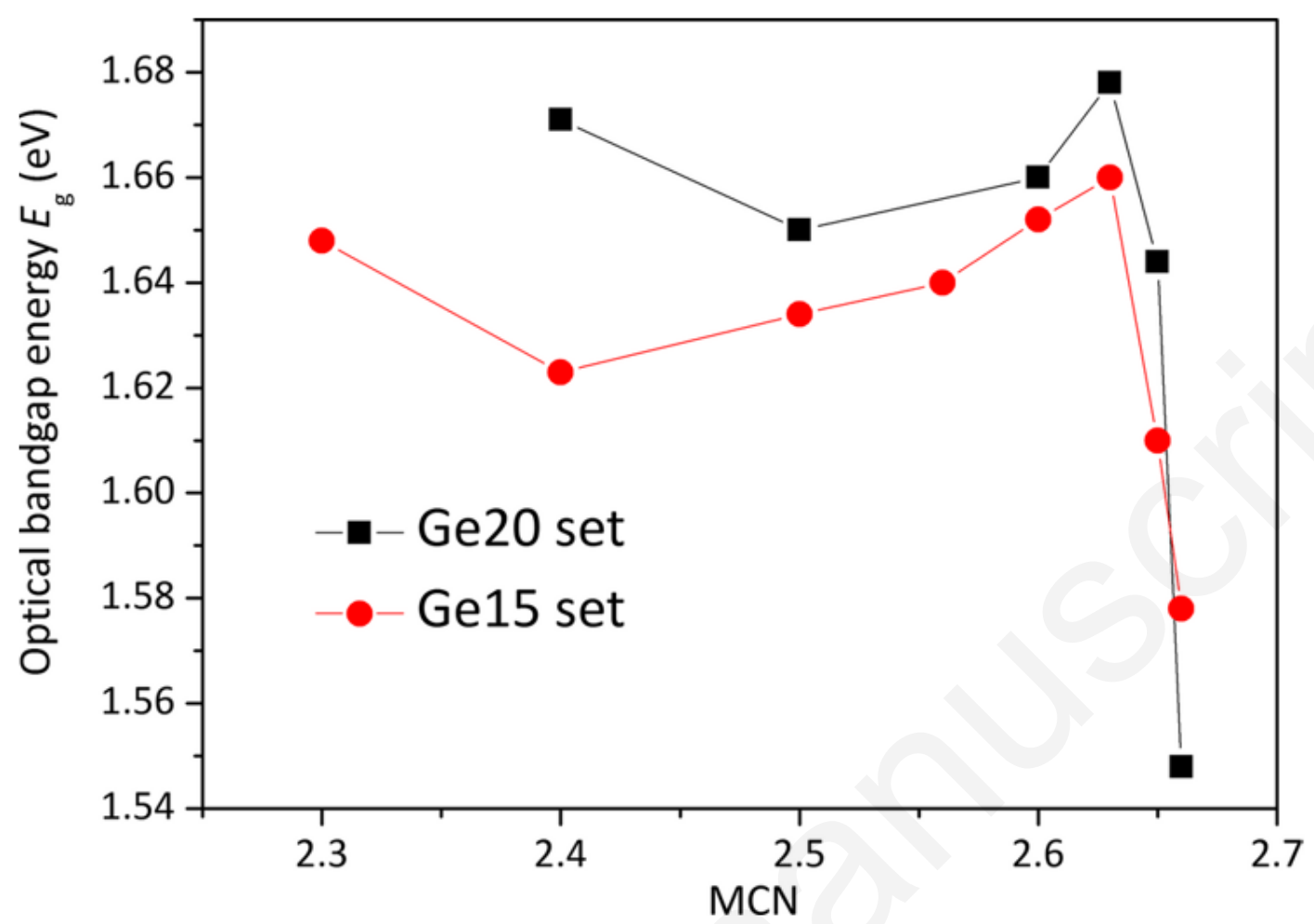

Fig. 4 The variation of the optical bandgap energy $\left(E_{\mathrm{g}}\right)$ with the mean coordinate number $(\mathrm{MCN})$ of the two Ge-Sn-Se glass sets. 


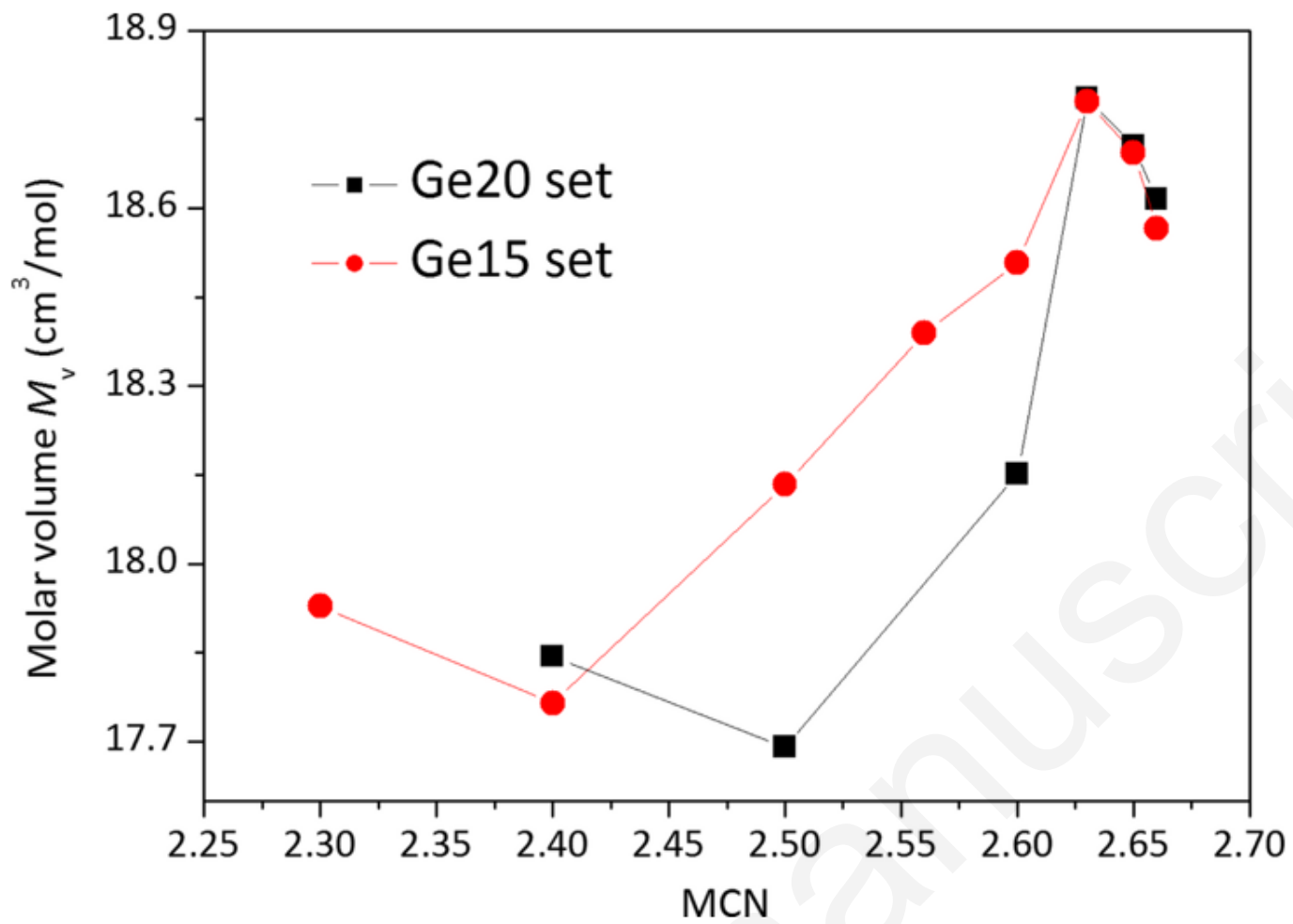

Fig. 5 The variation of the molar volume $\left(M_{\mathrm{v}}\right)$ with the mean coordinate number $(\mathrm{MCN})$ of the two Ge-Sn-Se glass sets. 

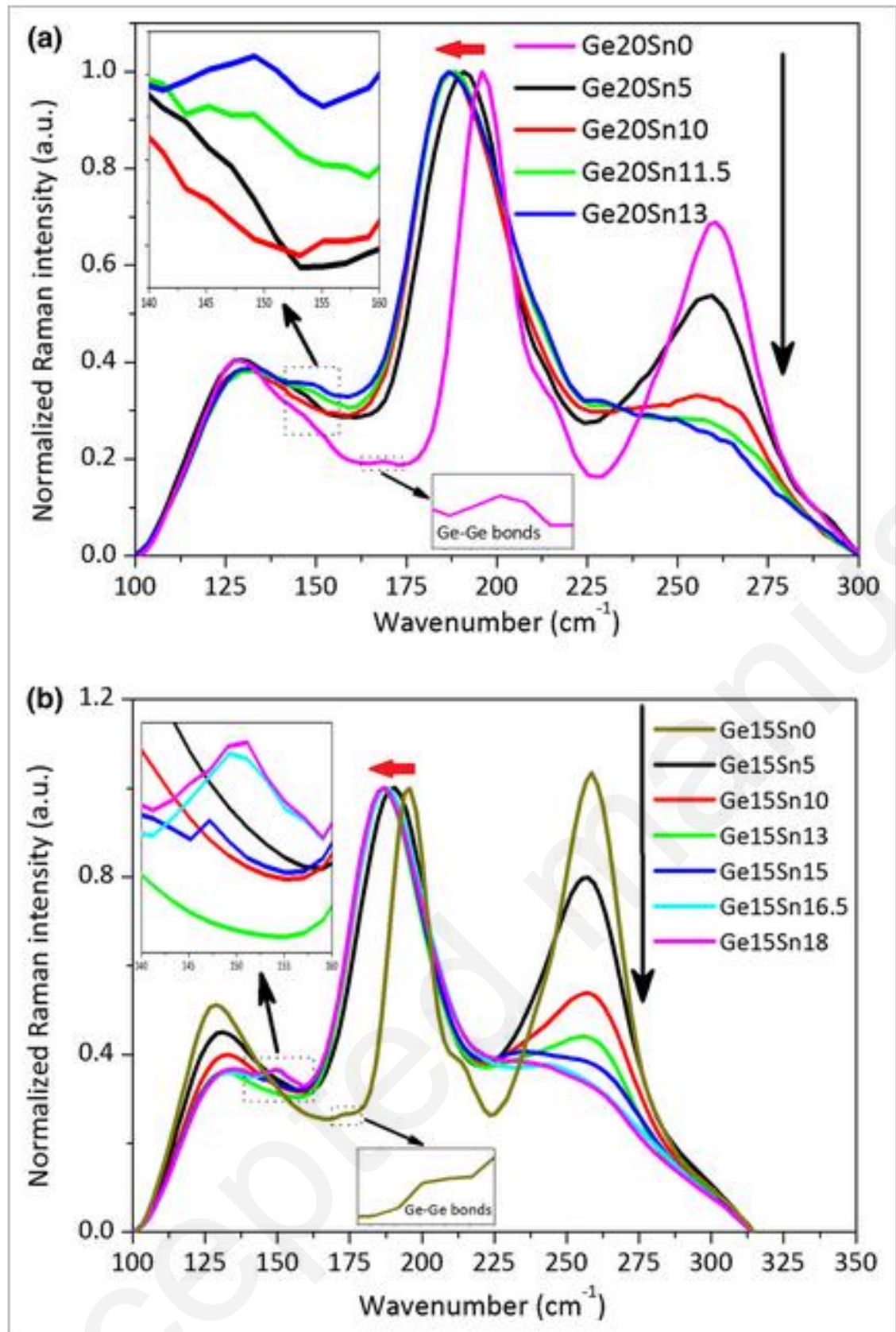

Fig. 6 Raman spectra of the Ge-Sn-Se glasses (a) Ge20 set and (b) Ge15 set. In the inset, Raman spectra are enlarged to show the present of Raman signal belongs to vibration of Sn-Sn and Ge-Ge homopolar bonds. The red arrow in each figure notes that the main Raman peak shifts to low energy region with addition Sn. 


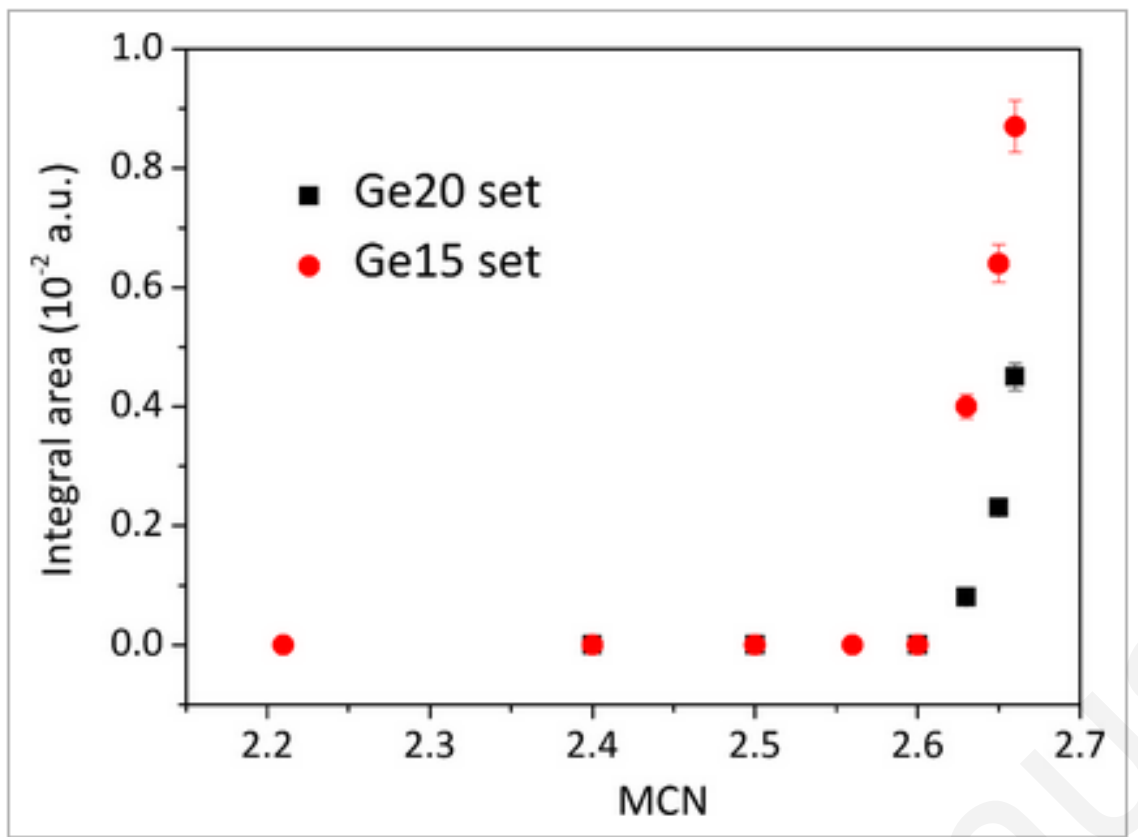

Fig. 7 The variation of integral area of Raman peak belonging to Sn-Sn homopolar bonds with the mean coordinate number (MCN) of the two Ge-Sn-Se glass sets. 


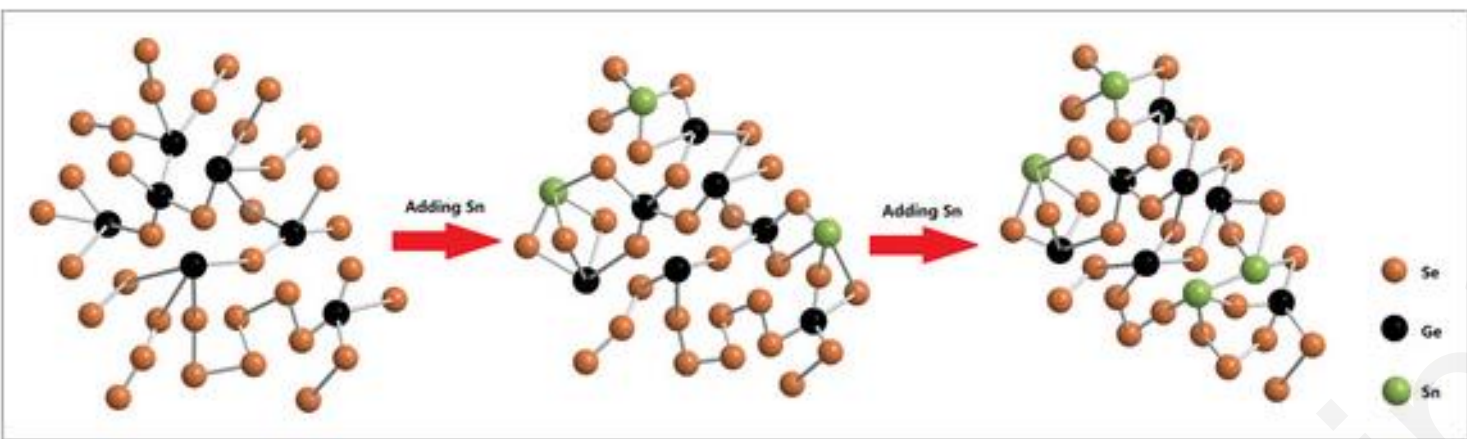

Fig. 8 A possible structural model of the Ge-Sn-Se glasses, and its evolution with incorporation of Sn. The number of atoms used is kept at 42 . 
TA B LE 1 Characteristic temperatures, density $(d)$, molar volume $\left(M_{v}\right)$ and optical bandgap energy $\left(E_{\mathrm{g}}\right)$ of Ge-Sn-Se samples

\begin{tabular}{|c|c|c|c|c|c|c|c|c|c|}
\hline Composition & Sample Label & $T_{\mathrm{g}}\left( \pm 1^{\circ} \mathrm{C}\right)$ & $T_{x}\left( \pm 1^{\circ} \mathrm{C}\right)$ & $\Delta T\left( \pm 2^{\circ} \mathrm{C}\right)$ & $d\left( \pm 0.001 \mathrm{~g} / \mathrm{cm}^{3}\right)$ & $M_{\mathrm{v}}\left( \pm 0.001 \mathrm{~cm}^{3} / \mathrm{mol}\right)$ & $\mathrm{MCN}$ & $E_{\mathrm{g}}( \pm 0.001 \mathrm{eV})$ & Appearance \\
\hline $\mathrm{Ge}_{20} \mathrm{Sn}_{0} \mathrm{Se}_{\mathrm{B} 0}$ & $\mathrm{Ge} 20 \mathrm{Sn} 0$ & 153 & - & - & 4.354 & 17.843 & 2.4 & 1.671 & Amorphous \\
\hline $\mathrm{Ge}_{20} \mathrm{Sn}_{5} \mathrm{Se}_{75}$ & $\mathrm{Ge} 20 \mathrm{Sn} 5$ & 217 & 377 & 160 & 4.504 & 17.690 & 2.5 & 1.650 & Amorphous \\
\hline $\mathrm{Ge}_{20} \mathrm{Sn}_{10} \mathrm{Se}_{70}$ & $\mathrm{Ge} 20 \mathrm{Sn} 10$ & 276 & 388 & 112 & 4.499 & 18.152 & 2.6 & 1.660 & Amorphous \\
\hline $\mathrm{Ge}_{20} \mathrm{Sn}_{11.5} \mathrm{Se}_{68,5}$ & Ge20Sn11.5 & 327 & 438 & 112 & 4.389 & 18.785 & 2.63 & 1.678 & Amorphous \\
\hline $\mathrm{Ge}_{20} \mathrm{Sn}_{12,5} \mathrm{Se}_{67.5}$ & $\mathrm{Ge} 20 \mathrm{Sn} 12.5$ & 331 & 438 & 107 & 4.379 & 18.705 & 2.65 & 1.644 & Amorphous \\
\hline $\mathrm{Ge}_{20} \mathrm{Sn}_{13} \mathrm{Se}_{67}$ & Ge20Sn13 & 334 & 411 & 77 & 4.431 & 18.615 & 2.66 & 1.548 & Amorphous \\
\hline $\mathrm{Ge}_{20} \mathrm{Sn}_{13,5} \mathrm{Se}_{66,5}$ & - & - & - & - & 2.586 & - & 2.67 & - & Crystalline \\
\hline $\mathrm{Ge}_{20} \mathrm{Sn}_{15} \mathrm{Se}_{65}$ & - & - & - & - & 2.547 & - & 2.7 & - & Crystalline \\
\hline $\mathrm{Ge}_{15} \mathrm{Sn}_{0} \mathrm{Se}_{\mathrm{B} 5}$ & $\mathrm{Ge} 15 \mathrm{Sn} 0$ & 121 & - & - & 4.351 & 17.929 & 2.3 & 1.648 & Amorphous \\
\hline $\mathrm{Ge}_{15} \mathrm{Sn}_{5} \mathrm{Se}_{80}$ & Ge15Sn 5 & 172 & 374 & 202 & 4.503 & 17.765 & 2.4 & 1.623 & Amorphous \\
\hline $\mathrm{Ge}_{15} \mathrm{Sn}_{10} \mathrm{Se}_{75}$ & Ge15Sn10 & 221 & 386 & 165 & 4.521 & 18.134 & 2.5 & 1.634 & Amorphous \\
\hline $\mathrm{Ge}_{15} \mathrm{Sn}_{13} \mathrm{Se}_{72}$ & Ge15Sn13 & 248 & 424 & 176 & 4.523 & 18.389 & 2.56 & 1.640 & Amorphous \\
\hline $\mathrm{Ge}_{15} \mathrm{Sn}_{15} \mathrm{Se}_{70}$ & Ge15Sn15 & 275 & 453 & 178 & 4.537 & 18.508 & 2.6 & 1.652 & Amorphous \\
\hline $\mathrm{Ge}_{15} \mathrm{Sn}_{16.5} \mathrm{Se}_{68.5}$ & Ge15Sn16.5 & 297 & 415 & 122 & 4.503 & 18.780 & 2.63 & 1.660 & Amorphous \\
\hline $\mathrm{Ge}_{15} \mathrm{Sn}_{17.5} \mathrm{Se}_{67.5}$ & Ge15Sn17.5 & 309 & 418 & 109 & 4.525 & 18.694 & 2.65 & 1.610 & Amorphous \\
\hline $\mathrm{Ge}_{15} \mathrm{Sn}_{18} \mathrm{Se}_{67}$ & Ge15Sn18 & 314 & 398 & 85 & 4.587 & 18.566 & 2.66 & 1.578 & Amorphous \\
\hline $\mathrm{Ge}_{15} \mathrm{Sn}_{18.5} \mathrm{Se}_{66,5}$ & - & - & - & - & 3.124 & - & 2.67 & - & Crystalline \\
\hline $\mathrm{Ge}_{15} \mathrm{Sn}_{20} \mathrm{Se}_{65}$ & - & - & - & - & 3.208 & - & 2.7 & - & Crystalline \\
\hline
\end{tabular}

TABLE 2 Bond energy of the chemical bonds in Ge-Sn-Se glasses

\begin{tabular}{lll} 
Bond & $\begin{array}{c}\text { Arithmetic bond } \\
\text { energy }(\mathbf{K c a l} / \mathbf{m o l})\end{array}$ & $\begin{array}{c}\text { Geometric bond } \\
\text { energy }(\mathbf{K c a l} / \mathbf{m o l})\end{array}$ \\
\hline Ge-Se & 49.1 & 47.4 \\
\hline Sn-Se & 47.4 & 46.8 \\
Se-Se & 44.0 & \\
Ge-Ge & 37.6 & \\
\hline Sn-Sn & 34.2 & \\
\hline
\end{tabular}

